\title{
Inclusive Classrooms and Art: A Comparative Study between Turkey and the UK
}

\author{
Munevver Meltem Zudovas \\ Marmara University \\ Turkey
}

\begin{abstract}
This article examines inclusive education within the context of art education in a sample of primary school settings in two countries: Turkey and the UK. The main focus of this study is on the challenges and opportunities presented to primary school teachers, head teachers and Special Educational Needs Coordinators (SENCOS) in catering for the needs of SEN children in art lessons within mainstream classrooms. This is examined under the main research question: How effectively does art education facilitate inclusive education? The most suitable way to understand the similarities and differences between the sample of Turkish and UK school settings and their inclusion policy and practice with a reference to visual arts classrooms was to utilise a comparative case study approach using qualitative data collection methods, namely, semi-structured interviews. The data supported the importance of inclusive education in the education system in the UK and Turkey and overall revealed positive outcomes for pupils. The study provided evidence of the positive and enabling role that art education can play in inclusive education. Several constraints were identified including class size, budget, training, resources and having a coherent policy framework. The study data highlighted the positive impact that having a coherent policy framework and implementation has had on the provision of inclusive education in the UK schools. The study established that whilst there are many differences between the two countries studied, there are several areas that Turkey can learn from the UK example.
\end{abstract}

\section{Introduction}

The view that although inclusion has been highly emphasised by the authorities in Turkey is the focus of this study, there are still weaknesses in the system that prevent schools from being fully inclusive. Moreover, with the change in the education system to an emphasis on examinations-based teaching, and the low status of visual art education in the society, the quality of art education in Turkey has been adversely affected due to the limited timeframe allocated to the visual arts. Although there are elective lesson hours for various subjects -including the visual arts, how frequently these classes are utilised as an elective is uncertain. Spohn [1] comments on this issue stating that due to the increased emphasis on tests for reading and maths lessons in schools, it is feared that arts subject will suffer.

In the UK inclusion has had a much longer history compared to Turkey. Therefore, Special Educational Needs (SEN) have been better adapted and accommodated within the school curriculum. Although Mary Warnock who prepared the Warnock Report [2] subsequently published an evaluative pamphlet [3]about inclusive education stating that the UK education system had failed to establish an inclusive society. She claimed that the government needed to re-evaluate and review the situation in the schools. She argued that there was a need to reconsider terms such as SEN, inclusion and state meeting in order to clarify the connection between social difficulties and SEN [4].

The principle underlying this study is that good visual arts lessons provide young people with an ideal environment in which to develop their creative ability and to produce individualistic art works themselves regardless of their special needs and disabilities. Furthermore, creative thinking skills are one of the key proficiencies that arts subjects can assist students to acquire in order to raise successful future generations. This would suggest that art education could play an important role in facilitating inclusive education.

Shevlin et al. [5] argue that the success of inclusive education relies on knowledge in the area, expertise, awareness, resources and viewpoints. Therefore, it is vital to give voice to stake holders' perceptions on the issue. The findings may then be used to inform policies and policy making in the field of inclusive/special needs education and art within both countries. This is one of the main contributions this article aims to make to this research area. 


\section{Methods}

The most suitable way to identify the similarities and differences in the policies as well as enquiring into classroom teachers' and management staffs' perceptions in two different countries was to employ a case study using three schools in each country. The 'case' of this particular research is the perceptions of art teachers and special needs educators on the role of art education in facilitating inclusive education in two countries, the UK and Turkey. The data analysis therefore provided a comparative perspective, looking for similarities and differences in the two countries' policy and practice.

\subsection{Participants}

In this research, the researcher has chosen to adopt purposive sampling. Teacher participants were chosen from among those who taught art classes for students with special educational needs in their classrooms in the UK and Turkish schools. In total, there were 18 participants, nine from the UK and nine from Turkey. In Turkey's case the participant teachers were art specialists, since art is taught by specialists from the KS1 third grade. The research sample and suitable research settings were based on three main criteria:

- the schools were required to offer inclusive education and have students with SEN in the current term,

- teachers were required to be teaching those students with SEN during term time

- they needed to be art specialists.

The schools selected are typical in terms of the education they offer, the environment, the school population and the number of teachers that work in the schools as well as in terms of provision for inclusive education.

\section{Enabling Arts for Disabled Individuals}

Until the 1970s, the arts, including visual arts, was generally practiced by non-disabled people. However, between 1960 and 1975, with the emergence of new Special Needs' policies, the disabled population started to be acknowledged and their rights more carefully protected. In Australia, the Broughton Art Society (the arts society for the then termed 'handicapped') focused on the arts and disabilities, and in 1973 the National Council on the Arts made a statement about art education and the need for it to be accessible to every part of society including disabled individuals. In addition, in the USA, the National Committee of the Arts for the Handicapped (today known as the Very Special Arts
(VSA) and active in more than 60 countries) was founded with the aim of creating a society where every disabled member learned by taking part in and getting pleasure form the arts. In 1975, the first 'Art Education and Special Education' conference was held and supported by the National Art Education and Illinois Art Council, where it was accepted that every individual had the right to receive an art education. In the UK, these developments were closely followed, and in 1976, SHAPE Arts, the first disability and arts establishment, was founded.

At a further VSA conference in 1977, it was emphasised that art education should be delivered in the 'least restrictive environment' preferably in an integrated educational environment. Thus, art teachers were beginning to recognise the position of art education in special education settings, even though their involvement in the process at that stage was voluntary [6].

Allrutz [6] claims that as art provision for schools was inadequate in terms of designated hours and the available budget, the solution might be for educators (Art teachers, Special Education Teachers and classroom teachers) to join forces to create a better art curriculum. It was also noted that art had been used for analysis, therapy or a link to learning, therefore art was usually associated with 'selfexpression', 'constructive use of leisure time', 'therapy', 'development of hand-eye co-ordination', and 'vocational competency' [6] when taught in special education settings. As can be seen later, these elements are important to this study.

In the Gulbenkian Report, which focused on the situation of art education in the UK, as mentioned earlier, there is a section designated for students with SEN. This was organised into subcategories, art education for gifted students, physically disabled, educationally sub-normal and emotionally disturbed students. The report claimed that arts subjects offer unlimited communication opportunities for SEN pupils via different art forms. It also highlighted that most teachers are not qualified enough in the arts and in Special Needs to deliver an effective curriculum. 'On the job' training was proposed as a solution to this.

\section{Studies on School Staff's Perceptions on Inclusion}

In order to create a better system for inclusive education, it is also important to look at stakeholders' opinions and perceptions of the current system. According to Woolfson et al. [7], school staffs' and parents' perception of inclusive education is a topic that researchers have frequently examined. New staff, a flexible curriculum, new teaching methods and a variety of learning materials are the areas usually considered where necessary changes are required to be made. It could be argued that 
removing obstacles to learning and having higher expectations are the two main stages to reach in order to achieve success in inclusion. Schools are also developing a better understanding towards barriers to learning.

\subsection{School Staff's Attitudes}

Woolfson et al. [7] argue that teachers' behaviour is often affected by their attitudes and expectations, which eventually has an effect on the successful or unsuccessful implementation of inclusion. In general, studies focusing on key school staffs' perceptions and attitudes have shown diverse results [8]. Some studies revealed that school staff tend to hold a positive view towards inclusive education [8], whilst other studies revealed that some teachers still preferred not to have SEN students in their classes [9].

\subsection{Barriers to Inclusive Education}

Another study refers to the preparation of IEPs and teachers' excessive concerns about these [5]. In Turkey, researchers revealed that IEPs are regarded as an obstacle to inclusive education since they are poorly prepared and sometimes not put into practice [10].

Pufpaff [11] divides potential barriers for inclusion into two sub-categories: access and opportunity barriers. Opportunity barriers are divided into five categories: policy, practice, attitude, knowledge and skill. Although her study focuses on children with Augmentative and Alternative Communication needs, it is possible to generalise these barriers for other needs and disabilities that pupils might have in a mainstream classroom setting. Inclusion is considered to be good practice when it encourages both disabled and non-disabled pupils in the same classroom.

\subsection{Support}

There is also a strong emphasis on the importance of Special Educational Needs Teaching Assistants (SENTA) in schools [5]. Teaching Assistants (TAs) are employed in some countries to assist and help SEN pupils in the classroom. Although this is not the case in the Turkey sample in the current study, in the UK sample, teaching assistants play a big part in facilitating inclusive education. However, especially with the changing structure of inclusive education and its varying demands, education, professional development and job structure for teaching assistants is an issue. Yet, given the range of student need, assistants are particularly important in giving one-toone attention when teachers have to carry on the lesson for the majority of the class.

\subsection{Training}

The literature reveals that teachers tend to have more positive attitudes towards inclusive education after receiving associated trainings [5]. As Horrocks et al. [12] point out, school staff should be sensitive to students' needs and have the required equipment in order to meet that need. Moreover, successful implementation of inclusive education leads to confident teachers [5], which would solve many of the problems that were mentioned earlier. However, teachers tend to have fewer expectations of their students when they are more sympathetic to students with SEN [7].

There is also a possibility that students with SEN might experience isolation in the classrooms. Therefore, schools need to make radical changes in their inclusive systems, because assessing students with SEN according to classroom standards will result in students being either successful or the opposite . Educating pupils with different needs and disabilities is a challenging process; therefore, there is a need for detailed and careful planning in education and by extension within the curriculum.

\section{Findings and Discussion}

This study set out to explore how key school staff perceive and experience inclusive education within the visual arts lessons in two countries, namely, Turkey and the UK. comparisons were made within and between both case studies and themes emerged such as policies, budget, and environmental issues during the interviews with participants in both countries. Although both countries have policies on inclusive education secured by law, there were major differences in practice. In the schools in Turkey, it was revealed that the understanding of inclusion is still not secure and that more time is needed for it to be practised fully by schools. The study identified that some of the practitioners in Turkish schools were not aware of the ways that they can make their school more inclusive and do not receive enough assistance and guidance on implementing inclusion in their schools. In the UK schools the findings revealed that teachers in the UK demonstrated a more robust understanding and application of inclusive education.

\subsection{Concerns and opportunities}

Education Policy - In both countries, adequate resourcing, classrooms, access to schools, resources, teacher training and INSET were the issues participants related to policy. However, most of these issues mentioned by the UK participants were viewed as consistent and well organised provisions (that may need improvement to address more issues), whereas Turkish participants found SEN policy 
implementation to be unsystematic. In the Turkish sample, the majority of participants were unanimous that a more robust policy that supports and informs teachers and other stakeholders would facilitate the process and promote inclusion activities.

Lee and Low [13] suggest that experience is important for inclusion. The data in this current study, revealed that experience contributes to teachers' confidence and plays an important role in inclusive education.

At the same time, participants stated that the training that teachers received (both undergraduate education and in-service training) is not sufficient, often inadequate, and not as effective as they should be.

Based on these results, a more thoroughly prepared inclusive education policy is needed in Turkey. Art education can be monitored through expectancies from art teachers to 'work within a variety of settings, including higher education, to reform and revise their conceptions of disability and promote art education practices that are equitable, accommodating, inclusive, and non-discriminatory' [14]. There is little attention paid to this area in the Turkish education policy. The majority of Turkish participants commented that inclusion is a relatively new concept in Turkish education settings and that a more specific policy focus is evolving.

In the UK, the support schools can get from external agencies are numerous, depending on the school's budget. Meanwhile in Turkey the help is limited to psychologists that RAMs can offer, and hospital support. As such, it would seem that the medical model still prevails in Turkey's policy framework. In the UK, there are a variety of specialist external support services. In Turkey, there is no clear system of external support offered to cater for the special educational needs of students other than the RAMs and GCTs. UK participants stated that provision for inclusion is successful in their schools and that they try to address different needs with additional support from outside agencies.

One of the issues raised by Turkish participants was the need for a separate division for inclusive education since it is still considered to be under special education (where segregated education is favoured) and individual perceptions are shaped accordingly. This confirms that in some countries special education is placed under the Ministry of Health rather than the Ministry of Education which might indicate that in some countries special educational needs are still viewed through a medical lens.

\subsection{Classroom Practice}

The current research has revealed that there are positive effects in the use of visual arts in inclusive education. Although the majority of constraints participants experienced related to education in general, some of them were also related to visual art lessons.

Art lessons might enable and assist those pupils who find verbal interaction unsatisfying and overwhelming through its non-verbal methods of interaction. Art offers the chance for mutual understanding between children with autism and their teacher or therapist and ascribes this to the fact that art education is relatively free from verbal communication and does not rely on an intellectual way of understanding as is the case with other curriculum subjects. The importance of expression, especially in students with SEN, was emphasised also by the participants of the present study.

These findings indicate that any movement towards promoting visual arts lessons in inclusive education in schools may result in an expansion of the students' involvement in their own development. This confirms the view that integration of visual arts lessons, cross-curricular activities and creative lesson plans, as is the case in the UK, would engender greater inclusion of students with SEN in Turkish schools. It also confirms the argument earlier that teachers need to have an in-depth understanding of inclusive education and ways in which they can achieve this in their classrooms.

\subsection{Environment}

Art teachers tend to focus on 2D subjects such as drawing or painting and are advised to use 3D aspects of arts as well [16]. Ideally various materials should be utilised which would give students the opportunity to choose the best materials that help them to express themselves. However, offering different art mediums in classroom would require schools to have a suitable learning environment. One of the main areas that participants complained about was lack of resources. In the first instance, since there is no funding for art education in Turkey, students are required to bring their own materials, an issue that was highlighted by the participants in this study. The venue for art lessons was one of the constraints emphasised by the Turkish participants since lack of studio space restricted the activities they can conduct in a classroom environment.

This issue is also closely related to structural design issues, such as, small classrooms with high numbers of students and not having a washbasin within the classroom to wash lesson materials after class finishes. It would appear that art studios were not considered to be a priority to include in the main building plan or even if it was included, throughout the years, with the increasing number of students, schools had to convert them to classrooms (like the case in Mehmet Akif Vocational Religious School).

Students' independence in their work usually results from the art teacher's way of working. UK 
participants were confident in their methods and stated that they differentiate their lessons whenever they feel it is necessary.

Turkish participants stated that their students do not want to have a different activity to their friends and want to participate and practice whatever their peers are doing during that lesson. Breaking a subject into sections was a method suggested by participants in the UK. Also, for some students, differentiating lessons and employing creative problem-solving skills might need to be adopted. On this issue, Turkish art teachers indicated that they use clues, or give examples from the same environment for students identified as having SEN to associate with but none of them mentioned breaking a subject into smaller sections.

\subsection{Experience}

In both participating countries, teachers' confidence and experience were discussed. Teachers in the UK appear to be more confident and knowledgeable about inclusive education than their Turkish counterparts.

Art teachers might feel challenged when they have a student with SEN in their classroom [16] especially when they do not have previous experience with the nature of the needs. In this regard, the present study supports and adds to the findings of Sak1z and Woods [10] that showed similar results in the school staff's perceptions.

Educators should understand that every student can learn if appropriate teaching styles and strategies are utilised. Participants from both countries showed a similar understanding on this. However, participants in the UK seemed to focus more on individual differences within the class and an appreciation of diversity whereas some Turkish participants stated that they expect students with SEN to participate and produce in art classes as much as their peers do.

\section{Implications}

Turkey - Based on the findings of the current research, the intent and objectives of the Turkish government's schemes that target inclusive education were perceived relatively positively by participants. In particular, its benefits for all pupils' socialisation were emphasised and it is seen as an opportunity for SEN and non-SEN students to learn to accept personal differences. However, there is a need for better provision and co-ordination of resources for teachers working towards having inclusive education in their classrooms.

Another issue revealed throughout the literature review was the lack of knowledge about Turkey in the area in international research. For instance, Turkey did not take part in the arts and cultural education in Europe project conducted by Baïdak et al. [17]. Such a study could have provided valuable information for this research and future research because there is a lack of information about Turkey related to the situations highlighted in this report. If extended to Turkey projects such as Baïdak et al. [17] might be supported to promote art education nationwide such as the little-known projects the Meline: education and culture in primary schools (n.a.) in Greece, or the TaiTai (n.a.) in Finland both of which focus on art education and to improve its facilities nationwide. Similar projects can also be developed for inclusive education. Similarly, although contributing to other international projects/reports such as OECD [18], specific areas related to education seem to be missing and this information would supply important data about the Turkish education system and present Turkey's education statistics in the international educational arena.

The number of students who benefit from inclusive education has been increasing each year, however, there still a large number of students who are not benefitting from it and, sometimes, full participation could not be ensured for those who are receiving inclusive education. This and the fact that the schools in the Turkish samples were using double shift days in order to cater for educational access signify the need for more schools to be built in order to accommodate all Turkish students at the same time during the school day. In Turkey there also were constraints that schools and teachers faced regarding embedding inclusion in the education process. A system similar to Italy, where special education support teachers are assigned after receiving 1150 hours theoretical knowledge plus 300 hours of training to ensure inclusion could be adopted in Turkey as well. In addition, visual art teachers can create an environment where they can share their experiences with SEN students and art activities that they successfully conducted in an inclusive classroom.

In terms of art education and inclusion practice, one method could also be introducing artists with SEN [19] to all students in both countries. Introducing people who have overcome their special needs through the arts could help SEN students to see them as role models. There are many examples historically including, for example, the renowned 19th century painter, Henri de Toulouse-Lautrec who had restricted mobility in his legs, Mexican painter Frida Kahlo who suffered from health problems related to body injuries sustained in an accident throughout her life, Impressionist painter Claude Monet who suffered from cataracts and lost his vision gradually, painter and photographer Chuck Close, who was severely paralysed after suffering from spinal artery collapse, conceptual artists Ryan Gander who is a wheelchair user, Architectural artist 
Stephen Wiltshire who has autism, photography, digital imaging and painting artist Alison Lapper who was born with phocomelia, and fibre artist Judith Scott who had Down Syndrome and was born mute and profoundly deaf. Introducing local artists who have special needs to students in schools can provide them valuable experience and enable them to acknowledge that everyone in the society makes a contribution [19].

\subsection{Implications for the UK}

Based on the findings of the current study, the practice of inclusion was seen positively among participants from the UK. Similar to the Turkish participants, they made reference to the socialisation of students. However, there was a more established understanding and broad comprehension of inclusive education. In particular, frequently updated policies on inclusive education in the UK have had a big impact on these practices. However, there were still some constraints in relation to the needs of students and other areas. The impact of culture on creativity [17] states that so as to develop creative education environment in schools, teacher training needs to be improved.

In Britain, art is taught by classroom teachers, 'these teachers usually have little or no art education background. They may not understand the developmental, social, and emotional milestones fostered in art making' [20], therefore, during teacher training programs, an art element might be included in their training to familiarise them with the subject.

\section{Recommendations for Further Research}

Researchers who are interested in the examining inclusion policies and the perspectives of stakeholders as well as studies of international comparison, could focus on the following areas of research:

- In order to make a comparison between policies, a content analysis of inclusion policies and National Curriculum in various countries could be done accompanied by the perspectives of practitioners at different levels in education.

- It would also be beneficial to replicate this study on larger and different populations including students with SEN and their parents. A more subject specific recommendation would be designing a lesson for visual arts and to conduct it with the classroom and evaluate it with the students to enable their voices to be heard and their views to be considered.
Longitudinal studies in the field would produce data that would show the changes on teacher's perceptions as they gain experience in teaching.

\section{Conclusion}

Based on the findings of the current study, the practice of inclusion was seen positively among participants from the UK. Similar to the Turkish participants, they made reference to the socialisation of students. However, there was a more established understanding and broad comprehension of inclusive education. In particular, frequently updated policies on inclusive education in the UK have had a big impact on these practices. However, there were still some constraints in relation to the needs of students and other areas. The impact of culture on creativity [17] states that so as to develop creative education environment in schools, teacher training needs to be improved.

In Britain, art is taught by classroom teachers, 'these teachers usually have little or no art education background. They may not understand the developmental, social, and emotional milestones fostered in art making' [20], therefore, during teacher training programs, an art element might be included in their training to familiarise them with the subject.

The aim to offer equal educational opportunities for all students and increasing the number of students with SEN in mainstream classrooms remains one of the main objectives in Turkey's and the UK education system. However, at the moment, inclusive education appears to be addressing a small range of needs of students in Turkey. The general assumption that 'inclusive education is for students with mental and physical needs' seems to remain and therefore some of the students with SEN seem to benefit more from inclusive education than their other peers with SEN. In addition, in Turkey some of the students' needs are not considered carefully within the school and education system so that their needs are attempted to be met as they surface throughout the education process, which results in teachers and school staff feeling unsure about the methods they need to apply to address specific needs. If policy makers take note of these challenges and how to overcome them, improvements in the area are hopeful.

In terms of visual arts, it is thought of as a subject that can help students socialise, prepare for real life, be creative. Although this understanding was present in both research settings, in the UK, schools seem to use more art integrated subjects compared to Turkey. Policy documents state that it is not a requirement for individuals to be talented in order to receive arts lessons, since art addresses all skill and age groups [19]. In the UK sample participants revealed that the understanding of 'art can be practiced only by talented' still exists, whereas in Turkey, art is still 
seen as a 'spare lesson' by some. Therefore, policy makers need to create a balance in the public eye for art to be valued and for arts to be taught more in schools, since it does not only support talented students but also encourages imaginative thinking skills and creativity. These are invaluable skills and knowledge for life.

\section{References}

[1] Spohn, C. (2008). Teacher Perspectives on No Child Left Behind and Arts Education: A Case Study. Arts Education Policy Review, 109(4), 3-12. DOI: 10.3200/AEPR.109.4.3-12.

[2] Warnock, M. (1978). Meeting special educational needs : a brief guide by Mrs. Mary Warnock to the report of the Committee of Enquiry into [the] Education of Handicapped Children and Young People / [for the] Department of Education and Science [and] Scottish Education Department [and] Welsh Office. London.

[3] Warnock, M. (2005). Special educational needs: a new look. No. 11 in a series of policy discussions. Retrieved 10.10.2012, 2012, http://www.batod.org.uk/index.php?id=/ articles/inclusion/Warnock2005.htm (Access Date:_17 June 2020).

[4] The Education and Skills Committee. (2006). Special Educational Needs, Report, together with formal minutes. London, The Stationery Office Limited.

[5] Shevlin, M., Kearns, H., Ranaghan, M., Twomey, M., Smith, R., and Winter, E. (2009). Creating inclusive learning environments in Irish schools: Teacher perspectives: Trim: National Council for Special Education.

[6] Allrutz, C. C. (1974). A Rationale for Teacher Education for Art Education: Special Education. Art Education, 27(8), 26-29. DOI: 10.2307/3191900.

[7] Woolfson, L., Grant, E., and Campbell, L. (2007). A comparison of special, general and support teachers' controllability and stability attributions for children's difficulties in learning. Educational Psychology, 27(2), 295-306.

[8] Avissar, G. (2003). 'Teaching an inclusive classroom can be rather tedious': an international perspective, Israel, 1998-2000. Journal of Research in Special Educational Needs, 3(3), 154-161. doi: 10.1111/1471-3802.00010.

[9] Sucuoğlu, B. (2004). Türkiye'de kaynaştırma uygulamaları: Yayınlar/araştırmalar (1980- 2005). Ankara Üniversitesi Eğitim Bilimleri Fakültesi Özel Eğitim Dergisi, 5(2), 15-23.

[10] Sakı, H., and Woods, C. (2014). Achieving inclusion of students with disabilities in Turkey: current challenges and future prospects. International Journal of Inclusive Education, 19(1), 21-35. DOI: 10.1080/13603116.2014.90 2122.
[11] Pufpaff, L. A. (2008). Barriers to participation in kindergarten literacy instruction for a student with augmentative and alternative communication needs. Psychology in the Schools, 45(7), 582-599. doi: 10.1002/pits.20311.

[12] Horrocks, J. L., White, G., and Roberts, L. (2008). Principals' attitudes regarding inclusion of children with autism in Pennsylvania public schools. Journal of autism and developmental disorders, 38(8), 1462-1473.

[13] Lee, L. W., and Low, H. M. (2013). 'Unconscious' inclusion of students with learning disabilities in a Malaysian mainstream primary school: teachers' perspectives. Journal of Research in Special Educational Needs, 13(3), 218-228.

[14] Blandy, D. (1994). Assuming responsibility: Disability rights and the preparation of art educators. Studies in Art Education, 179-187.

[15] INTO. (2009). Creativity and the Arts in the Primary School Paper presented at the Discussion Document and Proceedings of the Consultative Conference on Education 2009, Dublin.

[16] Bain, C., and Hasio, C. (2011). Authentic learning experience prepares preservice students to teach art to children with special needs. Art Education, 64(2), 33.

[17] Baïdak, N., Horvath, A., Sharp, C., and Kearney, C. (2009). Arts and Cultural Education at School in Europe. Brussels: The Education, Audiovisual and Culture Executive Agency (EACEA P9 Eurydice).

[18] OECD. (1998). Education at a Glance, 1998 OECD Indicators. Paris: OECD Publishing.

[19] Cox, S. (2007). Equal Opportunities. In S. Cox and R. Watts (Eds.), Teaching Art and Design, 3-11 (pp. 156168): Continuum.

[20] Loesl, S. D. (2012). The Adaptive Art Specialist: An Integral Part of a Student's Access to Art. In S. M. Malley (Ed.), The Intersection of Arts Education and Special Education: Exemplary Programs and Approaches. Kennedy Center, Washington: VSA. 